\title{
МЕЖПОЛУШАРНЫЕ АСИММЕТРИИ И ПРИНЦИПЫ ДИФФЕРЕНЦИАЛЬНОЙ НЕЙРОПЕДАГОГИКИ В ВЫСШЕМ ОБРАЗОВАНИИ
}

\author{
Москвин В.А., Москвина Н.В.
}

Российский государственный университет физической культуры, спорта, молодежи и туризма (ГЦОЛИФК), г. Москва, Россия

\begin{abstract}
Проанализированы взгляды на проблему преподавания с учетом индивидуальных особенностей функииональных асимметрий человека, рассмотрены принципы нейропедагогики, приведены исследования регуляторных процессов в спорте с учетом межполушарных отношений.
\end{abstract}

Ключевые слова: межполушарные асимметрии; нейропедагогика; высшее образование; произвольная регулячия человека.

Научные исследования последних лет свидетельствуют о развитии нового направления, которое можно обозначить как нейропсихологический подход к проблеме индивидуальных различий $[2 ; 3 ; 7-9 ; 11 ;]$. Концепция А.Р. Лурия [1] о парциальном доминировании зон мозга позволяет говорить о том, что нейропсихологические основы индивидуальных различий здоровых людей могут быть связаны с вариабельностью сочетаний парциального доминирования сенсорных и моторных признаков (что должно определять разный их вклад в процессы реализации высших психических функций). Было установлено, что у лиц с вариациями сочетаний признаков парциального доминирования моторных и сенсорных систем действительно выявляются определенные индивидуально-психологические особенности в виде разных стратегий обработки вербально-логической и зрительно-пространственной информации, различия в регуляторных процессах и в индивидуальных стилях эмоционального реагирования [2; 3; 7-9;].

Для изучения особенностей функциональных асимметрий человека в настоящее время используются методики А.Р. Лурия [1], направленные на оценку «парциального левшества» (или парциального доминирования определенных зон мозга), а также пробы других авторов, включенных в «Карту латеральных признаков». Данная методика в настоящее время достаточно широко применяется для выявления латеральных особенностей человека [7-9].

Анализ развития нейропсихологии индивидуальных различий и дифференциальной психофизиологии показывает, что эти науки имеют самое тесное отношение к проблемам обучения и воспитания, в том числе, и в спортивной деятельности. Одной из основных в этом плане является проблема леворукости. Однако, применительно к леворукости можно говорить о двух основных ее видах: наследственной (генетической) и патологической (вследствие пре- и перинатальных поражений мозга) [7-8]. Известно, что леворукость в ряде случаев носит компенсаторный характер (вследствие поражений и органической недостаточности левого полушария), что приводит к компенсаторному повышению активности правого полушария. Поэтому насильственное научение леворуких праворукому письму приводит к большей нагрузке на левое полушарие и опасности еще большей его декомпенсации. Из спортивной психологии также известно, что попытки обучать юных спортсменов посредством усиления и тренировок неведущего органа (руки, ноги), т.е. без учета индивидуальных особенностей функциональных 


\section{Education \& Science - 2016}

асимметрий, приводить к отрицательным результатам (в плане задержки развития и формирования спортивного мастерства) [4]. Проблема леворукости имеет большое значение в спортивной практике. Левый профиль асимметрии у борцов, боксеров, теннисистов, фехтовальщиков делает их крайне неудобными соперниками для чистых правшей. Феномен «леворукости» хорошо известен в спорте и обязательно учитывается опытными тренерами [4; 8-10;].

Отмечается необходимость учета возрастных особенностей учащихся в виде преобладания в школьном возрасте правополушарных функций и связанную с этим необходимость большего использования наглядно-образного материала. Выделяются и анализируются основные индивидуальные типы учащихся (аудиалы, визуалы и кинестетики), которые поразному проявляют себя в процессе обучения (особенности этих типов также обусловлены парциальным доминированием соответствующих зон мозга). Отмечается необходимость реализации дифференцированного обучения с учетом когнитивных стилей учащихся, говорится о необходимости использования разных способов обучения и воспитания в зависимости от особенностей функциональных асимметрий детей и подростков. Особенности функциональных асимметрий не только можно, но и необходимо использовать также и в спортивной педагогике [8-9].

Анализ развития нейропсихологии индивидуальных различий и дифференциальной психофизиологии (основанных на трудах А.Р. Лурия, В.Д. Небылицина, Е.Д. Хомской) позволяет выделить ряд проблем, которые имеют непосредственное отношение к образованию и решение которых может способствовать его оптимизации. Рассмотрим наиболее актуальные:

1. Проблема леворукости. В педагогическом процессе необходимы учет индивидуальных особенностей леворуких учащихся и отказ от насильственного научения их праворуких письму.

2. Связь индивидуальных профилей латеральности (ИПЛ) с разными стилями переработки вербально-логической («левополушарный тип») и зрительно-пространственной («правополушарный тип») информации.

3. Динамика функциональных асимметрий в онтогенезе. Необходимо учитывать особенности этой динамики и тот факт, что новую информацию школьникам необходимо давать с большей «опорой» на правополушарные функции.

4. Наличие разных стилей подачи учебной информации преподавателями и стилей усвоения (восприятия) такой информации учащимися в зависимости от ИПЛ. Возможны их совпадения или несовпадения (в последнем случае может наблюдаться когнитивный диссонанс).

5. Особенности применения способов психолого-педагогического воздействия преподавателем в зависимости от ИПЛ студентов и учащихся. В процессе обучения следует учитывать, что «левополушарные» индивиды в большей степени склонны к восприятию убеждающих, рациональных воздействий, а «правополушарные» - эмоциональных, внушающих, поскольку они являются более конформными.

6. Необходимость использования в педагогическом процессе специальных коррекционных и реабилитационных мероприятий (в том числе и нейропсихологических) для компенсации или восстановления работоспособности и функций соответствующих структур мозга, для их активизации и развития.

7. Необходимость использования знаний о корреляциях индивидуально-психологических особенностей с латеральными признаками в целях проведения адекватных профориентационных мероприятий и правильного выбора профессии учащимися.

Эти проблемы (круг которых далеко еще не исчерпан) позволяют говорить о развитии нового направления в образовании (связанного с нейропсихологией индивидуальных различий) - 
нейропедагогики (которая имеет такое же право на самостоятельное существование, как нейролингвистика, нейропсихология, нейропсихиатрия и др.). Впервые термин «нейропедагогика» был введен в научный обиход авторами данной статьи в 1997 г. [6] и сегодня ее можно определить как науку использования знаний дифференциальной психофизиологии, дифференциальной нейропсихологии, данных о мозговой организации процессов овладения разными видами учебного материала и учета совместимости вариантов ИПЛ учащихся и преподавателей в образовательном процессе [5-6; 7-9].

Нейропедагогика может быть отнесена к специальным направлениям педагогики, таким, как лечебная педагогика, тифлопедагогика, сурдопедагогика, олигофренопедагогика и др., которая охватывает, однако, не только (и не столько) патологию, сколько норму. Нейропсихологическая диагностика рассматривается как один из перспективных подходов к проблеме школьной неуспеваемости. Таким образом, нейропсихологический подход к изучению нормы имеет не только теоретическое, но и прикладное, практическое значение в области педагогики, в том числе, и в спортивной педагогики. Уже было сказано о том, что «левополушарные» индивиды в большей степени склонны к восприятию убеждающих, рациональных воздействий, а «правополушарные» - эмоциональных, внушающих, поскольку они являются более конформными. Все это имеет также прямое отношение к области взаимоотношений тренера и спортсмена. Для «левополушарных» индивидов допустимы негативные и критические замечания, что может их активизировать, а вот для «правополушарных» вербальные воздействия должны носить преимущественно положительный и позитивный характер.

Знания нейропсихологии и дифференциальной психофизиологии, на наш взгляд, должны использоваться в педагогическом процессе не только психологами, но и преподавателями. Эти данные необходимо шире использовать для оптимизации процессов воспитания и образования. Исходя из этого, актуальной является проблема разработки и введения соответствующих спецкурсов по нейропедагогике для преподавателей и будущих педагогов.

Рассматривая влияние образовательной среды учебного заведения на социализацию личности учащегося, необходимо отметить, что немаловажную роль здесь играют и стили преподавания, которые напрямую связаны с индивидуальными особенностями преподавателя и которые также должны быть рассмотрены в контексте нейропедагогики. В настоящее время совершенно определенно можно говорить о наличии разных стилей подачи учебной информации педагогами и о стилях восприятия и усвоения такой информации учащимся в зависимости от индивидуальных профилей латеральности, поскольку их несовпадения могут приводить к когнитивному диссонансу. Все это свидетельствует о том, что принципы нейропедагогики, изложенные нами ранее [5], имеют практическое значение для образования.

Исследование и выявления связи функциональных асимметрий с особенностями волевых и регуляторных функций человека имеет важное значение как в целом в спортивной психологии [9-10; 12-15;], так и в контексте преподавания раздела регуляторных особенностей человека в спортивной и дифференциальной психофизиологии.

Приведенные данные свидетельствуют о том, что применение знаний нейропсихологии индивидуальных различий и дифференциальной психофизиологии (основанных на трудах А.Р. Лурия, В.Д. Небылицина, Е.Д. Хомской), дают возможность в педагогике более тонко и точно определять индивидуально-психологические особенности учащихся. Необходимость усиления гуманизации образовательного процесса требует более полного учета индивидуальных особенностей студентов, полученные данные необходимо более активно использовать для решения проблем дифференцированного обучения и его индивидуализации. 


\section{Education \& Science - 2016}

Исследование выполнено при финансовой поддержке РГНФ, проект № 16-06-50146-а (ф): «Комплексное исследование индивидуальных особенностей регуляторных прочессов человека в норме и патологии (онтогенетические и психофизиологические аспекты)».

\section{Список литературы}

1. Лурия А.Р. Высшие корковые функции человека и их нарушения при локальных поражениях мозга (3-е изд.) / А.Р. Лурия. М.: Академический Проект, 2000. 512 с.

2. Москвин В.А. Межполушарная асимметрия и индивидуальные стили эмоционального реагирования // Вопр. психологии. 1988. № 6. С. 116-120.

3. Москвин В.А. Межполушарные отношения и проблема индивидуальных различий. М: Издво МГУ, 2002. 288 с.

4. Москвин В.А., Москвина Н.В. Леворукость в спорте высших достижений // Спортивный психолог. 2010. № 2 (20). С. 25-29.

5. Москвин В.А., Москвина Н.В. Нейропсихология и нейропедагогика // Тезисы докладов I Международной конференции памяти А.Р. Лурия. М.: Изд-во МГУ, 1997. С. 67.

6. Москвин В.А., Москвина Н.В. Основы дифференциальной нейропедагогики. Оренбург: РИК ГОУ ОГУ, 2003. $152 \mathrm{c.}$

7. Москвин В.А., Москвина Н.В. Индивидуальные различия человека (клинико-психологические и психофизиологические аспекты). М.: Изд-во ИСЭ, 2010. 267 с.

8. Москвин В.А., Москвина Н.В. Межполушарные асимметрии и индивидуальные различия человека. М.: Смысл, 2011. 367 с.

9. Москвин В.А., Москвина Н.В. Психофизиология индивидуальных различий в спорте. М.: НИИ спорта РГУФКСМиТ, 2013. 128 с.

10. Родионов А.В. Практика психологии спорта. Ташкент: Lider Press, 2008. 236 с.

11. Хомская Е.Д., Ефимова И.В., Будыка Е.В., Ениколопова Е.В. Нейропсихология индивидуальных различий. М.: Рос. пед. агентство, 1997. 282 с.

12. Moskvin V.A., Moskvina N.V. Psychophysiology and features volitional regulation sport university students // European Journal of Education and Applied Psychology. 2015. № 3, pp. 62-65.

13. Moskvina N.V., Moskvin V.A. Hemispheric asymmetry and features communication processes in sport psychology // European Journal of Education and Applied Psychology. 2015. № 3, pp. 59-62.

14. Moskvin V.A., Moskvina N.V., Shumova N.S., Kovalevski A.G. Tendency to risk and impulsiveness at students of sports university // Austrian Journal of Humanities and Social Sciences. 2015. № 7-8, pp. 80-84.

15. Moskvin V.A., Moskvina N.V., Shumova N.S., Kovalevski A.G. Control over the actions in sports psychology // Austrian Journal of Humanities and Social Sciences. 2015. № 7-8, pp. 84-86. 